\title{
Development and Optimization of Methscopolamine Bromide Gastroretentive Floating Tablets Using $3^{2}$ Factorial Design
}

\author{
Authors \\ Maninder Pal Singh', ${ }^{1}$, Manish Kumar², Ravi Shankar³
}

Affiliations

1 CT Institute of Pharmaceutical Sciences, Shahpur, Jalandhar Punjab

2 MM College of Pharmacy, Maharishi Markandeshwar (Deemed to be University) Mullana -Ambala

3 SHEAT College of Pharmacy, Varanasi

Key words

drug delivery, drug research, pharmaceutics

received 23.06 .2020

accepted 19.08.2020

published online 29.09 .2020

\author{
Bibliography \\ Drug Res 2020; 70: 576-582 \\ DOI 10.1055/a-1249-8186 \\ ISSN 2194-9379
}

(C) 2020. Thieme. All rights reserved.

Georg Thieme Verlag KG, Rüdigerstraße 14,

70469 Stuttgart, Germany

Correspondence

Manish Kumar

MM College of Pharmacy, Maharishi Markandeshwar

(Deemed to be University)

Mullana, Ambala-133207

Haryana

Tel.: + 9101731-304258

manish_singh17@rediffmail.com;

manishsingh170180@gmail.com

\section{ABSTRACT}

Purpose The aim of this study was to formulate methscopolamine floating drug delivery system to increase its gastro retention for further enhancement of absorption and overall bioavailability.

Method Direct compression method was used to formulate floating drug delivery system of methscopolamine bromide. Different amount of HPMC, PVP K25, and MCC were used for preparation of tablets.

Result The prepared tablets were evaluated for thickness, hardness, weight variation, floating lag time, swelling index and in-vitro drug release. All the formulations showed less than 10\% of weight variation. The hardness and thickness of all the formulations were within the range of $3.7-4.2 \mathrm{~kg} / \mathrm{cm}^{2}$ and $3.63-3.83 \mathrm{~mm}$ respectively. Floating lag time for all the formulations was reported in seconds. The degree of swelling was reported in range of $82.10-85.83 \%$. In vitro release was carried out for $24 \mathrm{~h}$. The maximum release was shown by F1 (93.947\%) while the minimum release was observed for $\mathrm{F} 4$ ( $90.420 \%)$. The best formulation was optimized on the basis of percentage cumulative drug release, floating lag time and swelling index. F1 found to be the best formulation. Further on analyzing the drug release mechanism, F1 found to exhibit korsmeyer peppas model of drug release.

Conclusion Floating gastroretentive tablet of methscopolamine bromide was successfully developed using direct compression method with potential to enhance the drug absorption and effective treatment of peptic ulcer.

\section{Introduction}

A quaternary ammonium derivative of scopolamine named methscopolamine bromide belongs to the class of anticholinergic drugs that inhibits gastric acid secretion. The drug acts by blocking the muscarinic acetylcholine receptors [1] and thus is used effectively for the treatment of peptic ulcer. The quaternary ammonium derivatives show limited absorption of $10-25 \%$ [2]. Thus, this poor absorption hinders the efficacy of methscopolamine bromide.

Floating drug delivery system is an approach by which we could retain the drug in stomach for longer period of time to achieve sufficient drug absorption [3-6]. When compared to the aqueous medium the system offers lower bulk density that helps the drug de- livery system to float in the gastric fluid. Several approaches like mucoadhesive system, swelling system, high density system, magnetic system and floating system have been developed to increase the residence time of drug in stomach [7-9].

However each of this system seems to offer some drawback like drug induced injuries that may range from local irritation to perforation may occur as a result of mucoadhesive system. On the other hand, patient may suffer from serious implications due to accumulation of swelling system in the stomach [10]. Floating drug delivery system is therefore selected in this research to achieve the desired aim. 
Gastric retention will prolong the residence time of the drug in stomach that will eventually results in greater and prolong therapeutic effect. This system will also overcome the problem of frequent dosing associated with the conventional dosage forms and can be used effectively for local stomach disorders [11]. Further this system requires simple and conventional equipment for manufacture and is also suitable for the drugs that are unstable or insoluble at intestinal $\mathrm{pH}$ and have absorption window at stomach [12]. After ingestion, these formulations remain confined to the gastric region and releases drug in a sustained and prolonged manner to maintain a continuous supply of the drug to its absorption site in the upper gastrointestinal tract $[13,14]$.

Thus the motto of this research was to develop a drug delivery system (floating drug delivery system) that will help to retain the drug in stomach for a longer period of time for improving its absorption properties.

\section{Materials and Methods}

\section{Materials}

Methscopolamine Bromide (assigned purity $99 \%$ ) was provided as a gift sample by Alkaloids Private Limited, Kolkata (India). HPMC, MCC and PVPK25 were procured from Thermo Fischer Scientific India Pvt. Ltd.( Mumbai, India)

\section{Methods}

\section{Melting point determination}

Capillary tube was used to determine the melting point of methscopolamine bromide. The melting point of an organic solid can be determined by introducing a tiny amount into a small capillary tube, attaching this to the stem of a thermometer centered in a heating bath, heating the bath slowly, and observing the temperatures at which melting begins and is complete

\section{Infrared spectral analysis}

Infrared spectral analysis is analytical tool to determine the presence of functional group in chemicals. It is identical tool to check authentication of drug. The IR spectra in transmission mode were obtained using $\mathrm{KBr}$ disc method in the spectral region $500-4000 \mathrm{~cm}^{-1}$ (Shi- madzu FTIR spectrophotometer), using a resolution of $2 \mathrm{~cm}^{-1}$. Obtained spectrum was compared with reference spectrum of methscopolamine bromide.

\section{Drug polymer stability study}

The preliminary interference study was carried out to eliminate the possibility of interaction of methscopolamine bromide with polymers like HPMC and MCC. The drug was kept with each of the above polymers in $1: 1$ ratio in a humidity chamber at a temperature of $40 \pm 20^{\circ} \mathrm{C}$ and $65 \pm 5 \%$ relative humidity $(\mathrm{RH})$ for one month. The samples were analyzed using FTIR spectroscopy. Pure drug and pure polymers were also kept in similar conditions and analyzed by IR spectroscopy.

\section{Experimental design}

A $3^{2}$ randomized factorial design was used and two factors at three levels; were evaluated by experimental trials of nine possible combinations. The concentration of HPMC K15M (X1) and MCC were selected as independent variables as depicted in (- Table 1). Percent swelling index and percent cumulative drug release was taken as dependent variables. The resulting data was fitted into Design-Expert Software (version 12.0 Stat-Ease, Inc., Minneapolis, MN) and analyzed statistically. The 3D response plots were generated to estimate simultaneous influence of HPMC and MCC on dependent variables.

\section{Preparation of floating drug delivery system}

The floating tablets were prepared by direct compression method [15]. Methscopolamine bromide, HPMC, PVP K25, and MCC were weighed, sieved through sieve no. 60 separately and homogeneously mixed with each other for half an hour in mortar pestle. Aerosil and Magnesium stearate were mixed at last. The homogeneous blend was then compressed by single punch manual tablet punching machine. The detailed composition of the tablet is detailed as underneath in > Table 1.

\section{Evaluation parameters for the prepared formulations}

\section{Pharmaceutical general parameters for tablet}

The prepared tablets were evaluated for official and unofficial parameters of tablets including thickness by Vernier calipers, hardness by Monsanto tester, friability by Roche fibriliator, weight variation and uniformity of content [16-18].

- Table $13^{2}$ full factorial design of methscopolamine bromide floating tablets.

\begin{tabular}{|c|c|c|c|c|c|}
\hline Formulation Code & Drug & $\mathrm{X} 1=\mathrm{HPMC}(\mathrm{mg})$ & $\mathrm{X} 2=\operatorname{MCC}(\mathrm{mg})$ & PVP K25 & Dependent variables \\
\hline $\mathrm{F} 1$ & 5 & $55(-1)$ & $30(+1)$ & 6 & \\
\hline $\mathrm{F} 2$ & 5 & $75(+1)$ & $20(0)$ & 6 & \multirow[t]{4}{*}{ Degree of Swelling } \\
\hline $\mathrm{F} 3$ & 5 & $65(0)$ & $20(0)$ & 6 & \\
\hline $\mathrm{F} 4$ & 5 & $75(+1)$ & $10(-1)$ & 6 & \\
\hline F5 & 5 & $75(+1)$ & $30(+1)$ & 6 & \\
\hline F6 & 5 & $55(-1)$ & $10(-1)$ & 6 & \multirow{5}{*}{$\begin{array}{l}\text { Percentage Cumulative Drug } \\
\text { release }\end{array}$} \\
\hline F7 & 5 & $65(0)$ & $10(-1)$ & 6 & \\
\hline F8 & 5 & $55(-1)$ & $20(0)$ & 6 & \\
\hline F9 & 5 & $65(0)$ & $30(+1)$ & 6 & \\
\hline F10 & 5 & $65(0)$ & $20(0)$ & 6 & \\
\hline
\end{tabular}


The tablets were further evaluated for their ability to float in the gastric environment by carrying out further evaluation parameters including:

In-vitro buoyancy test

The time taken by the tablet to rise to the surface of the liquid medium and floating lag time (FLT) was noted. The FLT was determined by placing the tablet in $200 \mathrm{ml}$ glass beaker containing $100 \mathrm{ml} 0.1 \mathrm{~N}$ $\mathrm{HCl}(\mathrm{pH} 1.2)$ at $37^{\circ} \mathrm{C}[19-21]$.

Total Floating Time (TFT)

The duration of time the dosage form constantly remained on the surface of medium was determined as the total floating time (TFT)
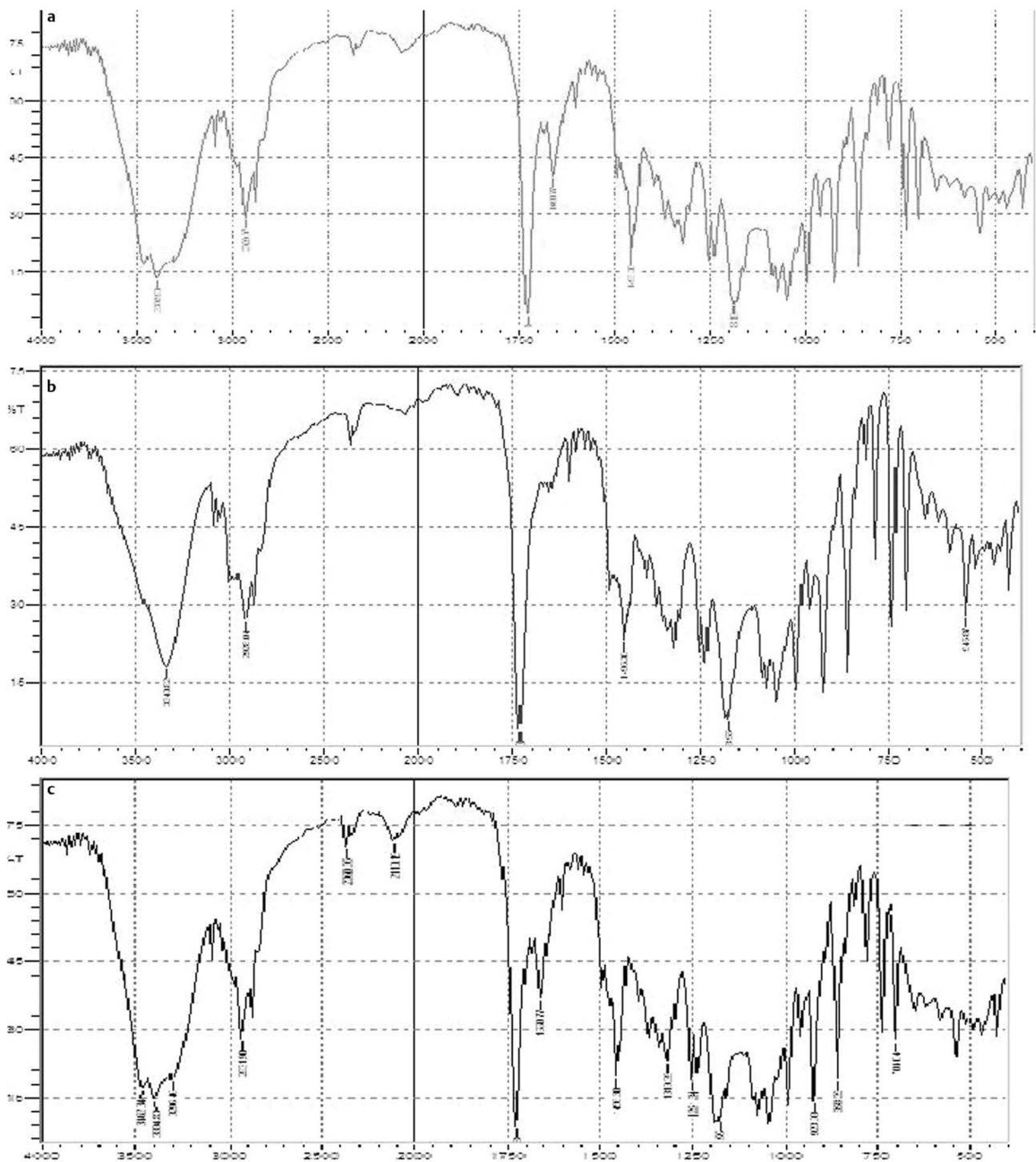

- Fig. 1 Drug polymer compatibility study a Drug, b Polymer and c Mixture. 
[19-21]. The TFT was determined by placing the tablet in $250 \mathrm{ml}$ glass beaker containing $200 \mathrm{ml} 0.1 \mathrm{~N} \mathrm{HCl}(\mathrm{pH} 1.2)$ at $37^{\circ} \mathrm{C}$.

\section{Swelling index}

Swelling of hydrophilic polymer such as Hydroxy Propyl Methyl Cellulose greatly depends upon the contents of the stomach and the osmolarity of the medium. These eventually influence the release of the drug from the formulation and also the residence time of the formulation in the stomach. One tablet was weighed and placed in a beaker containing $200 \mathrm{ml}$ of distilled water [11]. After each hour the tablet was removed from beaker and weighed again. This procedure was continued until constant weight was observed. The percentage weight gain by the tablet was calculated by using the formula.

$$
\mathrm{S} . \mathrm{I}=\mathrm{Wt}-\mathrm{Wo}_{\mathrm{O}} / \mathrm{Wo}_{\mathrm{O}} \times 100
$$

$\mathrm{Wt}=$ Weight of tablet at time $\mathrm{t}$

Wo $=$ Weight of tablet before immersion

In vitro release studies

In vitro drug release study of formulations were carried out according to USP dissolution apparatus USP XXII with using $900 \mathrm{ml} 0.1 \mathrm{~N}$ $\mathrm{HCl}(\mathrm{pH} 1.2)$ solution at $37 \pm 0.5^{\circ} \mathrm{C}$ with $50 \mathrm{rpm} .10 \mathrm{ml}$ of aliquot was withdrawn from the dissolution medium at specified time interval and dissolution media was replaced by fresh media. Dissolution studies were continued up to $24 \mathrm{~h}$. Samples were withdrawn and analyzed spectrophotometrically with addition of $0.1 \mathrm{ml}$ sodium picrate solution [22, 23].

\section{Analysis of drug release mechanism}

The release mechanism of methscopolamine bromide from prepared non effervescent floating tablets was determined by using different kinetic models like zero order, first order, Higuchi model, Korsmeyer-Peppas model.

\section{Result and Discussion}

\section{Drug polymer compatibility study}

Drug polymer interference study was carried out to eliminate the possibility of interaction of drug with polymer. FTIR of all the sam- ples were recorded ( $>$ Fig. 1). No predominant drug interaction was detected between drug and polymers along with excipients.

\section{Physical evaluation of floating tablets}

All the tablets of different batches were subjected to various evaluation tests such as thickness, hardness, friability, weight variation and drug content. The results are tabulated in > Table 2 . It was illustrated by the results that the formed tablets were within the limits prescribed as per weight variation test and uniformity of content test as prescribed by USP. The hardness of all the formulations was found to be in range of $3.7-4.2 \mathrm{~kg} / \mathrm{cm}^{2}$. Average thickness was found to be in the range of $3.63-3.83 \mathrm{~mm}$ and the tablets also passed the friability test as the weight loss of tablets were less than $1 \%$.

\section{Buoyancy studies}

The floating lag time was estimated in seconds for all the batches showing negligible lag time. The variation in total floating time was observed for the different batches. ( $\triangleright$ Table 3 ). With increase in the concentration of HPMC the total floating time was found to be increased. This increase in total floating time with concentration of polymer may be attributed to increase in swelling characteristics due to the entrapment of air [24,25]. Further in vitro release studies were performed to select the best formulation.

\section{Swelling studies}

Appropriate swelling property for FDDS was required for uniform and prolonged release of drug. The floating time and drug release profile were dependent upon swelling behavior of the tablets. Swelling index was calculated with respect to time. Swelling index increased as the weight gain by the tablets increased proportionally with the rate of hydration along with polymer concentration as shown in $>$ Table 4 . After $10 \mathrm{~h}$ no further increase in swelling index was observed. The extensive swelling of formulations will create a thick gel barrier, which retards and increases the path length for the diffusion of the drug molecules. It was found from the studies and confirmed by the design expert software also that selling index was directly proportional to the concentration of HPMC used in the formulation and MCC played a very much negligible role with slight decrease in swelling with increase in concentration as can be seen from $>$ Table 4 where considering the amount of HPMC $\left(X_{1}\right)$ con-

- Table 2 Physical evaluation of methscopolamine bromide floating tablets.

\begin{tabular}{|l|l|l|l|l|}
\hline Formulations & $\begin{array}{l}\text { Weight variation } \pm \text { S.D } \\
(\mathbf{n}=\mathbf{2 0})\end{array}$ & $\begin{array}{l}\text { Hardness } \pm \text { S.D } \\
\mathbf{( n = 3 )}\end{array}$ & $\begin{array}{l}\text { Percentage friability } \\
\mathbf{( n = 6 )}\end{array}$ & $\begin{array}{l}\text { Percentage drug } \\
\text { content } \pm \text { S.D } \\
(\mathbf{n}=\mathbf{3})\end{array}$ \\
\hline F1 & $120.2 \pm 5.8$ & $3.8 \pm 0.03$ & 0.718 & $98.22 \pm 0.07$ \\
\hline F2 & $121.2 \pm 4.3$ & $3.9 \pm 0.09$ & 0.702 & $98.01 \pm 0.06$ \\
\hline F3 & $119.7 \pm 4.9$ & 0.689 & $97.27 \pm 0.01$ \\
\hline F4 & $119.9 \pm 4.7$ & 0.722 & $3.73 \pm 0.05$ \\
\hline F5 & $118.5 \pm 5.8$ & $3.8 \pm 0.12$ & 0.721 & $3.77 \pm 0.04$ \\
\hline F6 & $120.1 \pm 5.2$ & $3.8 \pm 0.03$ & 0.719 & $3.69 \pm 0.05$ \\
\hline F7 & $119.7 \pm 4.9$ & $3.7 \pm 0.09$ & 0.695 & $96.23 \pm 0.06$ \\
\hline F8 & $120.2 \pm 7.5$ & $4.0 \pm 0.07$ & $3.67 \pm 0.03$ & $95.21 \pm 0.29$ \\
\hline F9 & $119.9 \pm 6.3$ & $3.9 \pm 0.06$ & $3.78 \pm 0.06$ & $94.38 \pm 0.04$ \\
\hline F10 & $121.1 \pm 3.2$ & $3.9 \pm 0.06$ & 0.713 & $93.45 \pm 0.07$ \\
\hline
\end{tabular}


- Table 3 Floating Lag Time (FLT) and Total Floating Time (TFT) of different formulations.

\begin{tabular}{|l|l|l|}
\hline Formulations code & Floating lag time $(\mathbf{s e c})$ & Total floating time \\
\hline F1 & 0 & $>20 \mathrm{~h}$ \\
\hline F2 & 2 & $>24 \mathrm{~h}$ \\
\hline F3 & 0 & $>22 \mathrm{~h}$ \\
\hline F4 & 4 & $>24 \mathrm{~h}$ \\
\hline F5 & 3 & $>22 \mathrm{~h}$ \\
\hline F6 & 0 & $>21 \mathrm{~h}$ \\
\hline F7 & 5 & $>23 \mathrm{~h}$ \\
\hline F8 & 4 & $>22 \mathrm{~h}$ \\
\hline F9 & 0 & $>21 \mathrm{~h}$ \\
\hline F10 & 0 & $>22 \mathrm{~h}$ \\
\hline
\end{tabular}

- Table 4 Optimization of data for selection of best formulation.

\begin{tabular}{|c|c|c|c|c|}
\hline $\begin{array}{c}\text { Formula- } \\
\text { tion Code }\end{array}$ & $\begin{array}{c}\mathrm{X}_{\mathbf{1}}=\mathrm{HPMC} \\
(\mathbf{m g})\end{array}$ & $\begin{array}{c}\mathrm{X}_{\mathbf{2}}=\mathrm{MCC} \\
\mathbf{( \mathbf { m g } )}\end{array}$ & $\begin{array}{c}\mathrm{Y}_{\mathbf{1}} \text { Degree } \\
\text { of swelling } \\
(\mathbf{\%})\end{array}$ & $\begin{array}{c}\mathrm{Y}_{\mathbf{2}} \text { Cumulative } \\
\text { drug release } \\
(\mathbf{\%})\end{array}$ \\
\hline F1 & $55(-1)$ & $30(+1)$ & 82.10 & $93.947 \pm 2.1$ \\
\hline F2 & $75(+1)$ & $20(0)$ & 85.67 & $90.635 \pm 0.52$ \\
\hline F3 & $65(0)$ & $20(0)$ & 84.09 & $92.660 \pm 0.80$ \\
\hline F4 & $75(+1)$ & $10(-1)$ & 85.83 & $90.420 \pm 0.40$ \\
\hline F5 & $75(+1)$ & $30(+1)$ & 85.52 & $90.865 \pm 0.90$ \\
\hline F6 & $55(-1)$ & $10(-1)$ & 82.39 & $93.102 \pm 1.8$ \\
\hline F7 & $65(0)$ & $10(-1)$ & 84.26 & $92.435 \pm 1.5$ \\
\hline F8 & $55(-1)$ & $20(0)$ & 82.25 & $93.525 \pm 1.2$ \\
\hline F9 & $65(0)$ & $30(+1)$ & 83.94 & $92.825 \pm 2.5$ \\
\hline F10 & $65(0)$ & $20(0)$ & 84.09 & $92.660 \pm 0.80$ \\
\hline
\end{tabular}

stant and increasing the amount of $\mathrm{MCC}\left(\mathrm{X}_{2}\right)$ as can be seen in batches F2, F4 and F5.

\section{In vitro release studies}

In vitro dissolution studies were carried out as per USP procedure by using $900 \mathrm{ml} 0.1 \mathrm{~N} \mathrm{HCl}$ solution at $37 \pm 0.5^{\circ} \mathrm{C}$ and the paddles were rotated at $50 \mathrm{rpm}$. Under fasted conditions, housekeeper waves clear the digested material from the stomach every $1.5-2 \mathrm{~h}$ [15]. When the tablet was taken orally, it remains in the stomach for $2 \mathrm{~h}$ and then expelled in the intestine. In case of floating tablets, release of drug was controlled. These studies were carried out for $24 \mathrm{~h}$. In all the formulations the amount of drug was kept constant i. e. $5 \mathrm{mg}$ which was the dose of the drug for controlled release. The concentration of HPMC plays a significant role in determining the rate of release from the floating tablets. It was found and is clear from $\triangleright$ Table 4 that the release rate of drug decreases with increase in concentration of HPMC. As evident from the table comparing formulation F4, F6 and F7 containing constant amount of MCC and varying concentration of HPMC, it was found that the release rate decreased with increase of HPMC concentration (> Fig. 2 ).

The above results clearly revealed that an increase in amount of HPMC has a slight effect on drug release. The reason may be the formation of denser hydrogel network which offers more hindrance to the drug release. Also due to extensive swelling with increase and diffusion path length with increase in concentration of polymer may lead to lower cumulative percentage release of drug.

\section{Optimization of formulations}

Optimization of prepared batches was done on the basis of floating lag time, swelling index and percentage drug release. An optimized formulation is defined as the one which was having minimum

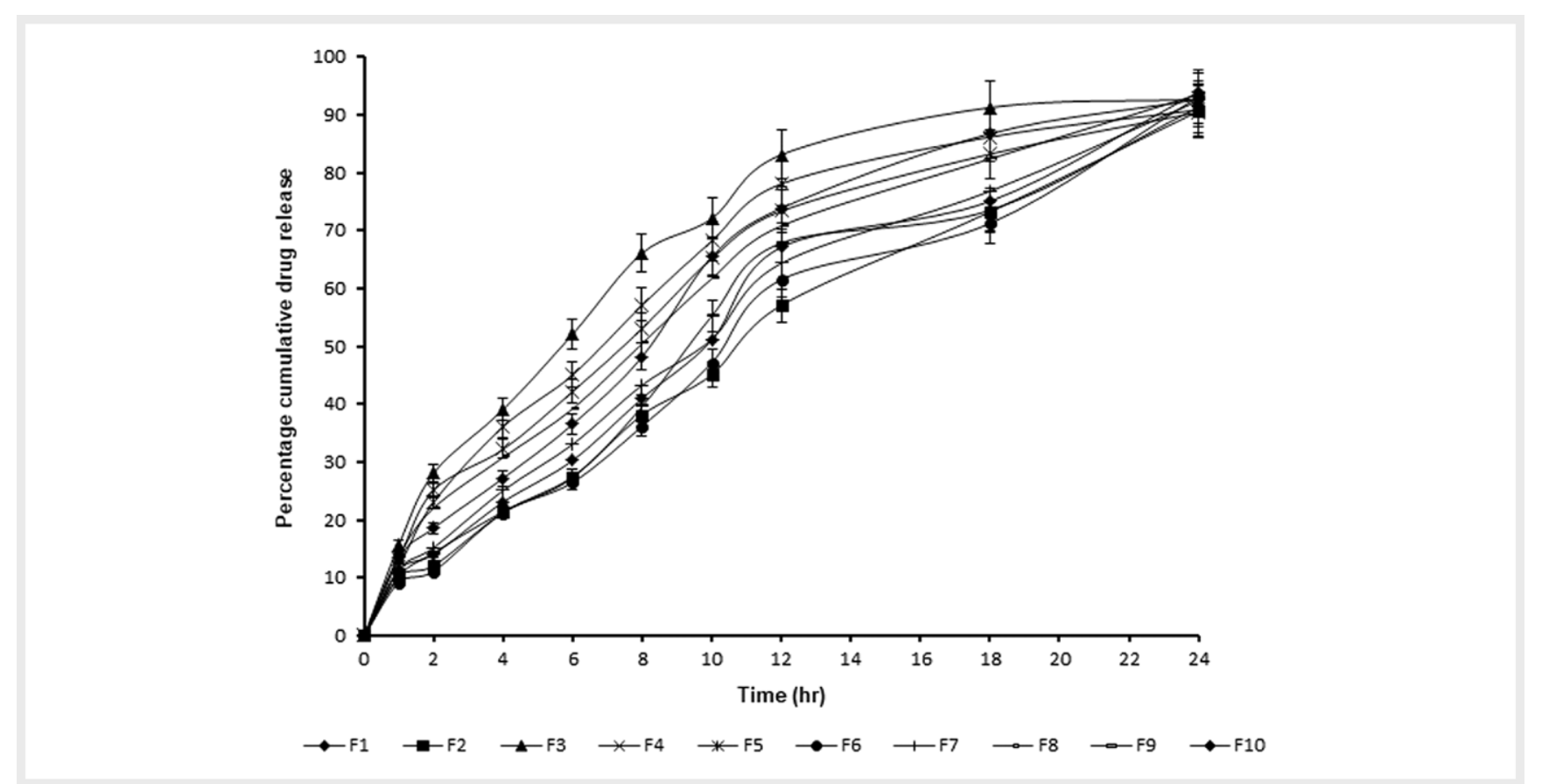

Fig. 2 Comparative in vitro drug release versus time graph. 
floating lag time, minimum swelling index and maximum drug release. Formulation F1 was found to exhibit all the desired properties of an optimized formulation ( $\triangleright$ Table 5 ).

\section{Analysis of release mechanism of optimized formulations}

All the formulations were subjected to zero order, first order, korsmeyer peppas model, higuchi model to examine the mechanism of drug release. In case of formulations F1 was found that the drugs release mechanism following the korsmeyer peppas model. The $n$ value in case of korsmeyer peppas model suggested whether the diffusion was fickian or non-fickian. The result suggested that drug release from two formulations (F6 and F9) followed fickian diffusion ( $\triangleright$ Table 5.) and rest followed non fickian anomalous transport. This shows that both fickian diffusion and non fickian diffusion play an important role in controlling the drug release

A statistical model with individual and interactive terms in the form of second order polynomial equation was used to evaluate the response variables: where $\mathrm{X}_{1}(\mathrm{HPMC})$ and $\mathrm{X}_{2}$ (MCC) are independent variables and $Y$ is the dependent variable. The terms including $A$ and $B$ represent the effect of single factor on the response variable on going from lower level toward higher, while the inter-

- Table 5 Regression coefficient values for different release mechanism for developed GRDDS formulations.

\begin{tabular}{|l|l|l|l|l|}
\hline $\begin{array}{l}\text { Formula- } \\
\text { tion code }\end{array}$ & $\begin{array}{l}\text { Zero } \\
\text { order }\end{array}$ & $\begin{array}{l}\text { First } \\
\text { order }\end{array}$ & $\begin{array}{l}\text { Higuchi } \\
\text { model }\end{array}$ & $\begin{array}{l}\text { Korsmeyer } \\
\text { Peppas model }\end{array}$ \\
\hline & Regression coefficient $\mathbf{( R}^{2}$ ) & \multicolumn{1}{l|}{} \\
\hline F1 & 0.792 & 0.832 & 0.949 & 0.920 \\
\hline F2 & 0.689 & 0.794 & 0.923 & 0.938 \\
\hline F3 & 0.714 & 0.728 & 0.921 & 0.932 \\
\hline F4 & 0.681 & 0.782 & 0.913 & 0.929 \\
\hline F5 & 0.721 & 0.782 & 0.937 & 0.923 \\
\hline F6 & 0.683 & 0.832 & 0.743 & 0.891 \\
\hline F7 & 0.745 & 0.632 & 0.823 & 0.937 \\
\hline F8 & 0.693 & 0.771 & 0.895 & 0.938 \\
\hline F9 & 0.785 & 0.821 & 0.762 & 0.754 \\
\hline F10 & 0.693 & 0.732 & 0.848 & 0.932 \\
\hline
\end{tabular}

active terms $(A B)$ show the combined effect of the two independent variables on the response parameter. The mathematical equation generated for the quantitative response parameters are expressed as:

Cumulative Release $=+92.65-1.44 \times 1+0.2800 \times 2-0.1000 \times 1$

$\times 2-0.5609 \times 1^{2}-0.0109 \times 2^{2}$

Degree of swelling $=+84.09+1.71 \times 1-0.1533 \times 2-0.0050$ $\mathrm{X} 1 \mathrm{X} 2-0.1357 \times 1^{2}+0.0043 \times 2^{2}$

In Equation (4) negative sign of coefficient of $A\left(X_{1}\right)$ indicates inhibitory effect on the response, and the large magnitude of coefficients showed that the factors pronouncedly reduces the drug release while positive sign of factor $B\left(X_{2}\right)$ indicates positive effect. In Equation (4) the positive sign indicates that HPMC K15M had positive effects on degree of swelling but the negative sign indicates negative impact on degree of swelling of factor $B$.

The relationship between variables was further elucidated using response surface plots. 3D bar surface chart drawn for graphical optimization of floating drug delivery system clearly shows the effect of independent variables MCC and HPMC K15M level on the response variables. It was observed that on increasing the levels of $\operatorname{HPMC}\left(X_{1}\right)$ and $\operatorname{MCC}\left(X_{2}\right)$ simultaneously, the degree of swelling increased in a significant form ( $\triangleright$ Fig. $\mathbf{3 b}$ ). While simultaneous increment of HPMC K15M and MCC has profound inhibitory effect on the drug release from the formulations ( $\vee$ Fig. 3a).

\section{Conclusion}

In the present work floating gastroretentive tablets of methscopolamine using different grades of HPMC were developed. The developed system with enhanced bioavailability will serve as a potential for treatment of peptic ulcer and other stomach related disorders. The tablets were prepared using direct compression method and subjected to various evaluation parameters. Among the various prepared formulations using different HPMC grade, F1 showed best results with respect to floating lag time, swelling index and in vitro drug release.
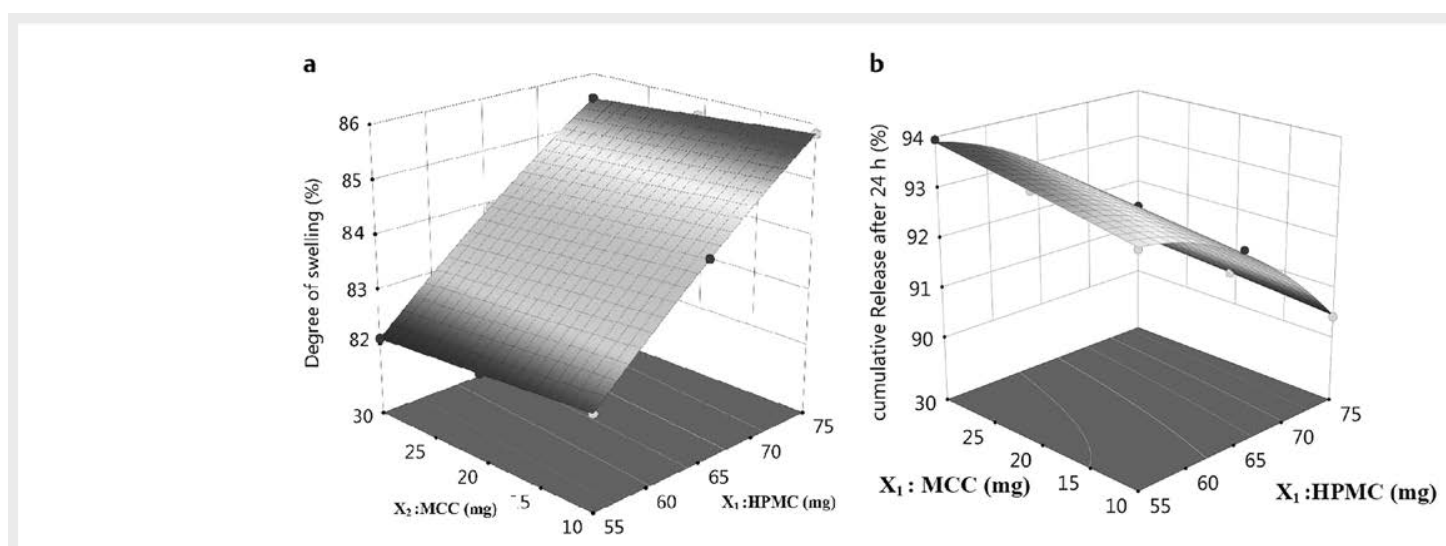

- Fig. 3 Surface Response Plot a Degree of swelling and $\mathbf{b}$ Percentage Cumulative drug released. 


\section{Acknowledgements}

We are thankful to Alkaloid corporation Pvt.Ltd. kolkata for providing the gift sample of methscopolamine bromide.

\section{Conflict of Interest}

The authors declare that there are no personal or financial conflicts of interest with individuals or organizations

\section{References}

[1] https://pubchem.ncbi.nlm.nih.gov/compound/methscopolamine_bromide

[2] https://www.parpharm.com/products/assets/pdf/MethscopolamineBromide-2018.pdf

[3] Whitehead L, Fell JT, Collett JH et al. Floating dosage forms: An in vivo study demonstrating prolonged gastric retention. J Controlled Release 1998; 55: 3-12

[4] Singh NB, Kim KH. Floating drug delivery systems: An approach to oral controlled drug delivery via gastric retention. J Controlled Release 2000; 63: 235-259

[5] Arora S, Ali ], Ahuja A et al. Floating drug delivery systems: A review. AAPS Pharm SciTech 2005; 3: E372-E390

[6] Bardonnet PL, Faivre V, Pugh W] et al. Gastroretentive dosage forms: overview and special case of Helicobacter pylori. J Controlled Release 2006; 111: 1-18

[7] Moes AJ. Gastroretentive dosage forms. Crit Rev Ther Drug Carrier Syst 1993; 10: 143-195

[8] Singh S, Pathak K. Assessing the bioadhesivity of Acconon MC8-2EP/ $\mathrm{NF}$ for gastroretention of floating microsponges of loratidine and achieving controlled drug delivery. Pharm. Biomed Res 2016; 2: 58-74

[9] Srikanth MV, Rao NS, Sunil SA et al. Statistical design and evaluation of a propranolol $\mathrm{HCl}$ gastric floating tablet. Acta Pharm Sin B 2012; 2: 60-69

[10] Sato $\mathrm{Y}$, Kawashima $\mathrm{Y}$, Takeuchi $\mathrm{H}$ et al. In vitro and in vivo evaluation of riboflavin-containing microballoons for a floating controlled drug delivery system in healthy humans. Int J Pharm 2004; 275: 97-107
[11] Klausner EA, Lavy E, Friedman M et al. Expandable gastroretentive dosage forms. J Controlled Release 2003; 90: 143-162

[12] Chen RN, Ho Ho, Yub YC. Development of swelling/floating gastroretentive drug delivery system based on a combination of hydroxyethyl cellulose and sodium carboxymethyl cellulose for Losartan and its clinical relevance in healthy, volunteers with CYP2C9 polymorphism. Eur J Pharm Sciences 2010; 39: 82-89

[13] Adebisi A, Conway BR. Gastroretentive microparticles for drug delivery applications. J Microencapsul 2011; 28: 689-708

[14] Streubel A, Siepmann J, Bodmeier R. Gastroretentive drug delivery systems. Exp Opin Drug Deliv 2006; 3: 217-233

[15] Rajani S, Panna T, Rajendra NS. In vitro and in vivo evaluation of gastroretentive floating drug delivery system of ofloxacin. Asian J Pharma Sciences 2013; 8: 191-198

[16] Rahman Z, Ali M, Khar RK. Design and evaluation floating labeled. Act pharm 2006; 56: 49-57

[17] United states Pharmacopeia 24-NF 19. 2000. Page No.296-297

[18] Indian Pharmacopeia 9th Ed, 1996. Page no. 135-136

[19] Roy P, Shahiwala A. Statistical optimization of ranitidine hydrochloride floating pulsatile delivery system for chronotherapy of nocturnal acid breakthrough. Eur J Pharm Sci 2009; 37: 363-369

[20] Gambhire MN, Ambade KW, Kurmi SD et al. Development and in vitro evaluation of an oral floating matrix tablet formulation of diltiazem hydrochloride. AAPS Pharm SciTech 2007; 8: E73

[21] Reddy LH, Murthy RS. Floating dosage systems in drug delivery. Crit Rev Ther Drug Carr Syst 2002; 19: 553-585

[22] Gaikwad VD, Yadav VD, Gaikwad D. Novel sustained release and swellable gastroretentive dosage form for ciprofloxacin hydrochloride. Int J Pharm Investig 2014; 4: 88-92

[23] Pawar HA, Gharat PR, Dhavale RV et al. Development and evaluation of gastroretentive floating tablets of an antihypertensive drug using hydrogenated cottonseed oil. ISRN Pharm 2013; 1-9

[24] Lingam M, Bhaskar K, Krishna C et al. Preparation of a matrix T type multiple-unit gastro retentive floating drug delivery system for captopril based on gas formation technique: In Vitro evaluation. AAPS Pharm Sci Tech 2008; 9: 612-619

[25] Streubel A, Siepmann J, Bodmeier R. Floating matrix tablets based on low density foam powder: Effects of formulation and processing parameters on drug release. Eur J Pharm Sci 2003; 18: 37-45 